Utah State University

DigitalCommons@USU

Extension Research

Extension

9-6-2018

\title{
Late-Career Unemployment Has Mixed Effects in Retirement
}

Maren Wright Voss

Utah State University, Maren.Voss@usu.edu

M. Beth Merryman

Towson University

Lisa Crabtree

Towson University

Kathy Subasic

Towson University

Wendy Birmingham

Brigham Young University

Lori Wadsworth

Brigham Young University

See next page for additional authors

Follow this and additional works at: https://digitalcommons.usu.edu/extension_research

Part of the Other Life Sciences Commons

\section{Recommended Citation}

Voss, Maren Wright, et al. "Late-Career Unemployment Has Mixed Effects in Retirement." Journal of Occupational Science, 2018, pp. 1-11., doi:10.1080/14427591.2018.1514645.

This Article is brought to you for free and open access by the Extension at DigitalCommons@USU. It has been accepted for inclusion in Extension Research by an authorized administrator of DigitalCommons@USU. For more information, please contact

digitalcommons@usu.edu.

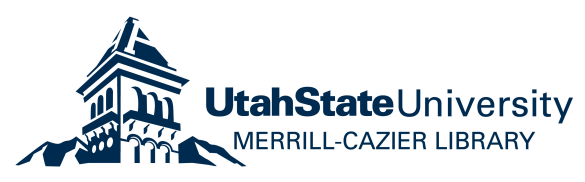




\section{Authors}

Maren Wright Voss, M. Beth Merryman, Lisa Crabtree, Kathy Subasic, Wendy Birmingham, Lori Wadsworth, and Man Hung 
2

Maren Wright Voss, $\mathrm{ScD}^{1,2}$; M. Beth Merryman, $\mathrm{PhD}^{3}$; Lisa Crabtree, $\mathrm{PhD}^{3}$; Kathy Subasic, $\mathrm{PhD}^{3}$; Wendy Birmingham, $\mathrm{PhD}^{4}$; Lori Wadsworth, $\mathrm{PhD}^{5}$; Man Hung, $\mathrm{PhD}^{2}$

\author{
${ }^{1}$ Utah State University Health and Wellness Extension \\ ${ }^{2}$ University of Utah School of Medicine \\ ${ }^{3}$ Towson University Department of Occupational Therapy and Occupational Science \\ ${ }^{4}$ Brigham Young University Department of Psychology \\ ${ }^{5}$ Brigham Young University Romney Institute of Public Management
}

Maren Wright Voss, ScD: Corresponding author

Utah State University, Health and Wellness Extension

100 East Center Street, L613

Email: maren.voss@usu.edu

Phone: 240-367-4777

Fax: 801-499-5371

ORCID: 0000-0002-9054-7389

M. Beth Merryman, $\mathrm{PhD}$

Towson University Department of Occupational Therapy \& Occupational Science

Enrollment Services 245, 8000 York Rd. Towson, MD 21252

Email: bmerryman@towson.edu

Phone: 410-704-3499

ORCID: 0000-0001-7041-1153

Lisa Crabtree, $\mathrm{PhD}$

Towson University Department of Occupational Therapy \& Occupational Science

Enrollment Services 245, 8000 York Rd. Towson, MD 21252

Email: 1crabtree@towson.edu

Phone: 410-704-5623

ORCID: 0000-0002-4590-7023

Kathy Subasic, PhD

Email: ksubasic@towson.edu

Phone: 410-704-5134

Wendy C. Birmingham, PhD 
41 Brigham Young University Psychology Department

421001 SWKT, Provo, UT 84602

43 Email: wendy_birmingham@byu.edu

44 Phone: $801-422-1648$

45

46 Lori Wadsworth, PhD

47 Brigham Young University Romney Institute of Public Management

48760 TNRB, Provo, UT 84602

49 Email: lori_wadsworth@byu.edu

50 Phone: $801-422-5956$

51 ORCID: 0000-0003-0163-7735

52

53 Man Hung, $\mathrm{PhD}$

54 University of Utah School of Medicine

55590 Wakara Way, Salt Lake City, UT. 84108

56 Email: Man.Hung@hsc.utah.edu

57 Phone: 801-587-5372

58 ORCID: 0000-0003-2827-3740

\section{Acknowledgements}

60 This work was supported by Quality Outcomes Research and Assessment

61 (http://QualityOutcomesResearch.com) and by Brigham Young University under a Gerontology

62 Program Grant award.

\section{Conflict of Interest}

64 None of the authors have any conflict of interest to disclose.

65

66 


\section{Late-Career Unemployment has Mixed Effects in Retirement}

70 Abstract

Paid work as a form of occupational engagement is an activity pattern that shifts both

72 during unemployment and during retirement. In cases where the retirement is involuntary, it

73 constitutes a form of lost work opportunity similar to unemployment. Occupational engagement

74 is a necessary element of health and wellness generally, and accordingly lost work opportunity

75 and the occupational deprivations it incurs have demonstrated negative effects on individual

76 level well-being. Unemployment and involuntary retirement have both been linked to poorer

77 physical and mental health outcomes. This paper analyzes work transitions during the pre- and

78 post- retirement years to gain perspective on the challenges of occupational deprivation that

79 might compromise health. A total of 24 retired individuals with late-career unemployment were

80 interviewed at the Huntsman World Senior Games in October 2016 and demographic data was

81 collected. Interviews were analyzed for relevant themes utilizing Braun and Clarke's (2006)

82 approach to thematic analysis and interpretations were evaluated against existing theory.

83 Results revealed that $1 / 6$ of individuals with unemployment just prior to retirement did not

84 classify this work displacement as unemployment. Themes identified included struggle, freedom,

85 and transition, followed by resilience and a return to well-being, with mental health levels

86 reported at national averages for the age group. Choice and autonomy in the retirement years

87 contributed to the noted resilience. Concepts of productivity and meaningful engagement shift

88 during the retirement years toward wellness derived from purposeful activity suggesting 
89 occupational models may need to reconsider concepts of productivity and purpose for this age

90 group.

91

Key Words: unemployment; involuntary retirement; choice; resilience; occupation

92

Word Count: 6299

93 


\section{Background}

While the construct of work is multi-cultural and linked to survival (Primeau, 1996), the construct of retirement is not. Retirement as a life stage, defined as the cessation of all paid labor, appears to have originated in industrialized nations during the late 1800's, possibly as an oversupply of labor pushed economies to shelve older workers and make way for younger, more productive employees (Weisman, 1999). At some point the concept shifted from the idea of being dismissed into inactivity to its current conceptualization as a desired and wished-for rest from labor. But in this evolving dynamic there is insufficient consideration given to the necessity of occupation and activity to human health.

Sociological studies demonstrate that work provides psychosocial benefits in addition to income. In the Great Depression era of broad failures in global economies, there was a renewed appreciation of the importance of work and activity to individual well-being. It was during depression-era studies in Europe that Jahoda (1982) and fellow researchers (Jahoda, Lazarsfeld, \& Zeisel, 1974) identified five latent benefits of employment that are lost when opportunities to engage in productive labor are unavailable. These latent benefits include: 1) rhythms of time use that allow an orderly sequence to the day's activity, 2) the availability of social interaction which can provide access to social support, 3) the opportunity to participate in collective purposes which supplies meaning to individual activity, 4) a social status through work which supports a feeling of acceptance in society, and 5) a defined personal identity that organizes perceptions of self (Jahoda, 1982).

The latent benefits of work theory may be relevant to health in aging and retirement, as evidence suggests that ongoing occupational engagement improves health in aging populations 
117 (Clark et al., 2012; Glass, de Leon, Marottoli, \& Berkman, 1999). Based on this understanding of 118 the importance of occupational engagement in an aging context, one question to consider is 119 whether a loss of work opportunity in the pre-retirement years would be any different in terms of 120 occupational disruption than a planned retirement. There is evidence to suggest that late-career 121 unemployment impacts retirement timing and may impact health in retirement. When individual 122 unemployment benefits run out, retirement rates rise for workers aged 62-69 (Coile \& Levine, 123 2011). Additionally, when economic recessions occur in the years just before an individual's 124 retirement age, individual level health declines for that age group (Burgard, Ailshire, \& 125 Kalousova, 2013). Economic recessions have been linked to cognitive function decline in older 126 adults (Leist, Hessel, \& Avendano, 2014). Loss of meaningful activity due to unemployment 127 may be at the root of the observed health declines. Survival analysis at a population level has 128 indicated that a one percent increase in unemployment rates occurring at age 58 resulted in a $12910 \%$ increase in the likelihood of morbidity by age 79 (Coile, Levine, \& McKnight, 2012). Research demonstrates that unemployment has a negative impact on health, and that 131 older workers are disproportionately impacted by unemployment. In the US in 2010, workers 132 over age 55 who lost their jobs experienced an average of 43 weeks of unemployment, compared to just 32 weeks for younger workers (Van Horn, Corre, \& Heidkamp, 2011). It is also evident 134 that older workers are more likely to leave the workforce permanently when unemployment 135 strikes. Only 10 percent of displaced factory workers aged 20-54 were absent from the labor 136 force 3-5 years after a job loss, compared with roughly 30 percent who permanently left the labor 137 force among those aged 55-69 (Coile \& Levine, 2011).

There is a broad body of literature that has found that the loss of a job leads to reductions 139 in both physical and mental well-being. Broad population level evidence links unemployment to 
140 higher rates of overall mortality due to cardiovascular disease or suicide (Gerdtham \&

141 Johannesson, 2003; Granados, House, Ionides, Burgard, \& Schoeni, 2014; Jin, Shah, \& Svoboda,

142 1995; Stuckler, Basu, Suhrcke, Coutts, \& McKee, 2011; Sullivan \& Von Wachter, 2009). Of

143 particular relevance, unemployment experienced among older adults has been shown to have

144 lasting effects on mental health (Voss et al., 2017), and these negative effects do no dissipate

145 when there is a return to work (Gallo et al., 2006). Given both theory and evidence of the

146 importance of work opportunity for the health of populations, it is interesting to consider whether

147 loss of work during retirement produces similar negative health effects. There is a clear trend

148 toward declining health and life satisfaction in the years following formal retirement (Moon,

149 Glymour, Subramanian, Avendano, \& Kawachi, 2012). A meta-analysis of 22 longitudinal

150 studies on the health effects of retirement concluded that retirement produces short-term

151 increases in mental health, but found conflicting evidence for the impact on physical health (van

152 der Heide, van Rijn, Robroek, Burdorf, \& Proper, 2013). To understand this conflicting

153 evidence requires breaking down the broad group of retirees with sub-group analysis.

154 Voluntariness of the retirement experience is proving to be a critical element in understanding its

155 health effects as involuntary retirees have more negative health outcomes (Van Solinge, 2007).

156 Approximately 1/3 of the 2006-2010 participants in the US Health and Retirement Study (HRS)

157 reported their retirement as involuntary and on average experienced health declines following

158 retirement, while those with voluntary retirement had no negative health effects (Rhee, Mor

159 Barak, \& Gallo, 2016). In terms of well-being, only voluntary retirees showed significant

160 increases in overall happiness following retirement (Calvo, Haverstick, \& Sass, 2009).

The transition to retirement, particularly if involuntary and preceded by unemployment,

162 places added burdens on the organization of time and activity, which can challenge occupational 
163 balance and well-being (Matuska \& Christiansen, 2008). The purpose of this study is to describe 164 the impact of late-career unemployment in the context of its close chronological connection to 165 retirement and its impact on voluntariness of retirement to assess how this type of occupational 166 disruption might impact individual well-being. This type of examination can be conducted 167 applying qualitative phenomenological methods.

\section{Methods}

The goal of the qualitative interviewing was to unfold an understanding of the people, the contexts, and the interaction between late-career unemployment and retirement well-being.

Participants. Semi-structured qualitative interviews were conducted with 24 adults over

173 age 50 who had experienced unemployment within 10 years of retirement. Interviews were part

174 of a larger project by the authors on retirement health, drawn from data collected from 176

175 retired individuals attending the Huntsman World Senior Games held in Utah, USA, during

176 October 2016. The Huntsman World Senior Games is an activity based conference that provides

177 opportunities for seniors to compete in both athletic (baseball, volleyball, pickleball, etc.) and

178 non-athletic (bridge, shooting, shuffleboard, etc.) events. As the nature of qualitative research is

179 necessarily intrusive into the thoughts and perceptions of individuals (Creswell, Klassen, Plano

180 Clark, \& Smith, 2011), the research protocol was reviewed and approved by the Institutional

181 Review Boards of Brigham Young University, Towson University, and the University of Utah to 182 ensure the proper protection of human subjects.

Data collection. Participants provided informed consent for study participation. All

184 research personnel were trained following the Collaborative Institutional Training Initiative

185 protocol. Quantitative responses regarding physical health, mental health, employment history, 
and demographic status were collected using a Qualtrics survey administered on electronic tablets at the time the participants were recruited at a Huntsman World Senior Games health fair. Self-reported physical health was collected by respondents' answer to the question, 'Would you say your health is excellent, very good, good, fair, or poor?' Self-reported health has been found to be a reliable indicator of health outcomes (Cheak-Zamora, Wyrwich, \& McBride, 2009;

Salyers, Bosworth, Swanson, Lamb-Pagone, \& Osher, 2000). Mental health was assessed using the Center for Epidemiological Studies-Depression (CES-D) measure (Radloff, 1977).

Participants were instructed to leave blank any questions they felt uncomfortable answering. This instruction, while a protective component advised by IRB, resulted in missing data on some survey questions such as income and retirement voluntariness. Data are stored on a University secure server accessible only by research personnel and was collected utilizing a participant ID without attached identifying information. Semi-structured interviews were electronically recorded and administered utilizing a moderator guide which was pilot tested on 20 mature individuals. Screened partitions separated interview booths from the general traffic of the health fair. Information about retirement timing, time-use, control, health, and well-being status were queried in each interview. No constraints were placed on interview length, but interviews tended to range between 15-40 minutes with few exceptions.

Data analysis. There were two components to our data analysis, deductive and inductive. The theory-driven deductive component of analysis drew upon the occupational science view that occupations are elemental in the ongoing development and well-being of individuals (Jahoda, 1982; Jonsson \& Persson, 2006; Matuska \& Christiansen, 2008). The theory-driven element was instituted in selection of interview questions and the development of the moderator guide (see Appendix A) and informed by theories of occupational well-being. Thematic analysis 
was conducted as recommended by Braun and Clarke (2006) using an inductive method which

210 allowed for exploratory consideration of emergent themes. Data-analysis which uses a bottom-up

211 approach, where codes and themes are identified from the data rather than determined a priori,

212 emphasizes individual level meanings in data analysis (Braun \& Clarke, 2014; Smith \& Osborn,

213 2008). The semi-structured interview format guided by theory-driven queries, then followed by

214 emergent thematic analysis, resulted in a combined deductive and inductive analytic approach.

Interviews were transcribed by trained research assistants and the primary investigator

216

conducted a first reading to code blocks of text that could be identified as characteristics of the

217 described experience, using an initial open coding level of analysis. Analysis was performed

218

using NVivo software for Mac 11.0 ("NVivo qualitative data analysis Software," 2014). NVivo

219 is a software system that allows selections of text to be highlighted during the coding process and

220 that text can then be associated to key word or code for later identification and thematic analysis.

221 This code-highlighting during the interview text-reading process is consistent with an emergent

222 story-telling approach to thematic analysis. A coding table was constructed in NVivo software

223 from the generated codes and patterns. Theoretical codes were developed following the open

224 coding, and while informed by occupational models, were phrased to reflect wording arising

225 from individual stories. New codes were added as themes emerged in the ongoing coding

226 process (see Appendix B). A second reading was conducted to apply the coding table to all

227 interviews, and the coding table was modified as new coding categories were identified in the

228 second coding. Emerging codes were compared with substantive and theoretical codes derived

229 from the first reading. Patterns of experience that occurred with frequency across interviews

230 were identified as relevant themes arising from individual level experiences. On the third and

231 final reading, quotes which exemplified the identified themes were added to the coding table 
232 (Braun \& Clarke, 2006). Data trustworthiness was addressed through the inclusion of quotations 233 that exemplified the themes and confirm their accuracy. Credibility of the data and its

234 transferability to relevant theory was the focus of the methodological design, rather than

235 empirical generalizability (Smith \& Osborn, 2008). In addition, cross-comparisons between the

236 US HRS national dataset (Chien et al., 2015) and the complete Huntsman Senior Games research

237 project were made. Themes were evaluated as coherent or disruptive to the time, meaning, and

238 control elements of occupational balance theory as it relates to mature populations.

239

240

241

242

243

244

245

246

247

248

249

250

251

252

253

254 255

\section{Findings}

The first step of the analysis was to identify the relevant cohort who had experienced unemployment, drawn from the full interview sample. Twenty-four individuals from the 176 participants in the larger study were identified as having late-career unemployment using a combination of survey and interview data. Demographic information was provided by 18 of the 24 participants and is summarized in Table 1 . The 18 individuals were $94.4 \%$ Caucasian (compared to $83.1 \%$ in the national sample) and had a mean age of 71.1 (compared to 79.1 years in the national sample). There were $77.8 \%$ who were married and $5.6 \%$ widowed which was lower than national averages (52.2\% married and 31.6\% widowed) possibly due to the younger mean age of the Huntsman World Senior Games study participants. The sample was highly educated (55.6\% college graduates compared to $22.2 \%$ nationally in this age group) and $55.5 \%$ reported income over $\$ 50,000$ annually (national mean income $\$ 58,973$ ). This group of older adults had CES-Depression scores at the national average (mean=1.36 compared to national mean $=1.34$, range $=0-8$ ) and self-rated health scores higher than the national average (mean=1.94 compared to national mean=3.02; where $2=$ very good and $3=$ good). 
Table 1: Demographics of unemployed individuals who completed the survey data $(\mathrm{N}=18)$

\begin{tabular}{|c|c|c|c|c|c|}
\hline \multicolumn{2}{|l|}{ Variable } & \multirow{2}{*}{$\frac{\mathbf{n}}{18}$} & \multirow{2}{*}{$\frac{(\%)}{72.0 \%}$} & \multirow{2}{*}{$\frac{\text { Mean (SD) }}{71.1(7.25)}$} & \multirow{2}{*}{$\begin{array}{r}\text { Range } \\
62-90\end{array}$} \\
\hline Age & & & & & \\
\hline \multirow[t]{4}{*}{ Race } & Black/African & 1 & $5.6 \%$ & & \\
\hline & American & & & & \\
\hline & White/Caucasian & 17 & $94.4 \%$ & & \\
\hline & Other & 0 & $0.0 \%$ & & \\
\hline \multirow[t]{2}{*}{ Gender } & Male & 10 & $55.6 \%$ & & \\
\hline & Female & 8 & $44.4 \%$ & & \\
\hline Marital & Married & 14 & $77.8 \%$ & & \\
\hline \multirow[t]{3}{*}{ Status } & Divorced & 2 & $11.0 \%$ & & \\
\hline & Widowed & 1 & $5.6 \%$ & & \\
\hline & Never Married & 1 & $5.6 \%$ & & \\
\hline \multirow[t]{4}{*}{ Education } & Less than HS & 0 & $0.0 \%$ & & \\
\hline & HS Graduate/GED & 3 & $16.6 \%$ & & \\
\hline & Some College & 5 & $27.8 \%$ & & \\
\hline & $\begin{array}{l}\text { College Graduate } \\
\text { and above }\end{array}$ & 10 & $55.6 \%$ & & \\
\hline \multirow[t]{6}{*}{ Income } & $<\$ 15,000$ & 0 & $0.0 \%$ & & \\
\hline & $\$ 15,000-\$ 29,999$ & 1 & $5.6 \%$ & & \\
\hline & $\$ 20,000-\$ 49,999$ & 5 & $27.8 \%$ & & \\
\hline & $\$ 50,000-\$ 69,999$ & 6 & $33.3 \%$ & & \\
\hline & $>\$ 70,000$ & 4 & $22.2 \%$ & & \\
\hline & Missing & 2 & $11.0 \%$ & & \\
\hline
\end{tabular}

259 not report an episode of unemployment in response to the survey questions. Transcript analysis

260 showed that these $16.6 \%$ were pushed into early retirement by job loss, highlighting a tendency

261 toward under-reporting unemployment episodes when they occur in the pre-retirement years. The

262 blurry distinction between early retirement and unemployment is evident in the statements of

263 individuals describing their retirement decision.

264 Well, uh, I actually got pushed out a little bit." 
Oh, well it wasn't really my decision, they closed down the office where I worked so I, and luckily I was only 55 and they gave me early retirement.

It wasn't voluntary in that they came to me and said hey, the situation here. We

And then I retired. ...she had to let me go because (the) company closed their need to cut back on people. We'll give you a year severance package if you would retire today. If you don't want that severance package, we're going to have to let you go.

\section{3} pre-retirement years emerged from coding transcripts. These included; 1) a time of struggle - the

274 distinct challenges of facing unemployment at an older age, 2) a time of freedom - the

275 importance of freedom and autonomy in life satisfaction, 3) a time of transition - the necessity of 276 adaptation on multiple levels, and 4) a time of resilience - the tendency of focusing on benefits in 277 the present rather than problems of the past.

279 impact on life, "All I had to do was get my resume out there to a few, interviews, salary 280 negotiations, and that was it. Yea it wasn't a big deal." For the majority, there is no doubt that 281 the experience of unemployment late in a career was a distinct challenge. Higher unemployment rates disproportionately impact older adults, resulting in an increased length of unemployment

283 (Coile \& Levine, 2011; Coile et al., 2012). For many, choosing to retire seemed to be their best 284 or only option. so the jobs were not available then, that was not a good time for looking. 
The experience of ageism in re-employment, or at least the perception of ageism was

288 evident in some cases. One woman let go from her job at age of 65 suspected ageism. Others

289 felt re-employment was difficult due to ageism, "I was without work for 10 months after that

290 because no one wants to hire a 52-year-old ex-airline employee." And for others, the issue of

291 age was more personal than corporate, "It was just that I didn't want to look for a job at 62."

292 For those who struggled with the unemployment and lay-offs, the effects were both

293 economic and emotional.

I started working (at) a third of what I had been making before...It was an adjustment, it was, it was a time of trial, and uh I passed it. Not without a lot of anguish and problems.

297 The loss of health benefits and the high costs of health insurance premiums were mentioned as 298 challenges by two participants. "Well the Obamacare truly was too expensive." so I chose eating. I figured that was going to be healthier than using insurance because I didn't eat. unemployment would need to work an additional 3.5 years to recoup the lost retirement income (GAO, 2012). This estimate was the reality for one participant who informed us, "I lost probably 305 three years, you know, because I had to work the three years to make up full retirement." Other 306 individuals past the age of 50 were either reluctant to seek re-employment or were discouraged

307 from doing so, taking early retirement with reduced incomes. Thus it would appear that the 308 challenges and limitations had a greater impact than if a similar unemployment episode might 
309 have occurred at a younger age. The long-lasting impact was not directly from the

310 unemployment as much as the interaction of age and retirement decisions related to the

311 unemployment occurring later in life.

A time for freedom. The second theme to emerge from the interviews was the high value

313 these older adults placed on freedom. The restrictions in choice they experienced related to

314 income and job options occurred just at a time when freedom was expressed as a highlight of the 315 life stage.

I'm still busy, it's just on my own time, doing what I want to do, that's the best part.

I'm freer than I was before because I don't have a job to hold me back.

I get to do whatever I want to do. I don't have to march to anyone else's tune. opinion.

322 Notice that the expression of freedom was often tied to the construct of doing, expressed as 323 freedom to 'do' whatever one chooses. There is a great deal of importance for older adults in 324 feeling they have a choice in their activities, as this choice provides a sense of control in life 325 more generally (Rudman, Cook, \& Polatajko, 1997). Choice in retirement has also been strongly 326 linked to health outcomes (Quine, Wells, De Vaus, \& Kendig, 2007). 328 autonomy, was expressed by many. "I love the freedom. I've always said I like time more than 329 money." And this was echoed by another, different words, but almost exactly the same 
330 sentiments. "Retirement doesn't pay as well as employment, (but) there are other benefits."

331 Even working choices in retirement continued to value time over money.

And it's been nice to have a little more time and a little more flexibility. That's the upside of only working part time. You're able to devote a little more time to your health and exercise.

It's kind of a hobby job. When you have, when you have a skill, people come to you and ask you to do things.

Well when I worked full time, I was expected to be there from 9, sorry from 9-5 and now I can work Saturdays, Sundays, I can take off for a week or two and go to a national tennis tournament or come somewhere like this and if I don't work I don't get paid but then I have the freedom to move about.

My favorite thing about being retired? Is being able to do whatever I want to do. And I think that my boss understands that, because I think she wants me, to keep me still working.

So even when paid work was the chosen activity in retirement, the opportunity to work in flexible arrangements fit the theme of freedom as a key aspect of the retirement experience.

A time of transition. As individuals discussed their choices and their adjustment process, a common theme was a non-linear nature to the retirement transition. Orderly transitions from full-time work to full-time ease were not the norm. The reasons for this curvilinear process were complex. While at times impacted by income or employment conditions, they were generally more existential and relevant to retirement as a life stage. 
One man described rapid and disruptive lifestyle changes in retirement. "I ended up

352 spending time with my wife 24/7. It's too much! You need some apart time to appreciate each

353 other better." This couple had sold a home, lived in an RV for 2 years, and then bought and sold

354 two additional homes before settling into a comfortable retirement lifestyle. Their retirement

355 decisions brought them face to face with new climates, new family living arrangements, and new

356 environmental hazards, all of which required either adaptation or changes of circumstance. It can

357 be hard to achieve the desired quality of life when there are so many unfamiliar options available

358 on the road to well-being.

Leaving a lifestyle of work can be a difficult adjustment and retirement does not stick for

360 everyone. This was true of the participant who went to work because, "I got tired of being

361 bored." Additionally, the idea of wishing the retirement decision had gone differently was

362 common. "If I had to do it over again, I would take a 90 day leave of absence and go back to

363 work."

364 People didn't always spend the time as they had planned during their retirement years.

I guess before I retired I had lots of things, lists, that I might want to do during retirement...I thought of volunteering various places, tutoring children, lots of different things. After I had that time home, I thought, I don't want to do any of those things!

368 In the majority of retirement stories shared, there was an element of the unexpected, of different trajectories and life choices, and almost always a theme of adjustment. Which speaks to another emergent theme, a pattern of resilience.

A time of resilience. The themes which emerged from the life stories of older adults 
373 transformation. Among the retirees experiencing unemployment in the years prior to leaving

374 work behind, there was often a decision point which opened the door to regret. A promotion or

375 transfer to a new position left someone more vulnerable to precarious employment and a later job

376 loss or their chosen early retirement reduced financial security in unexpected ways. The feeling

377 of having made a mistake was common. One man chose not to take an offered transfer out of

378 state which would have secured a better pension. The feeling of loss was only realized years

379 later, as the pension income wasn't meeting daily needs and desires for comfort in retirement. In

380 the moment of decisions, the twists and turns of a future existence can be impossible to predict.

381 Yet resilience was evident in almost every case, regardless of the level of regret.

382 Comments on resilience and adjustment arose unprompted, as individuals reflected on their

383 challenging experiences. It seemed that these retirees were quite adept at accepting the current

384 reality of their life circumstance and had moved into a place of relative peace.

...someone indicates they no longer value you, and you can't help but take it hard a little

One individual stated it simply as, "I should have stayed. But I'm happy now." Another

389 similarly found peace, "Well I would have like to have worked another 5 years but since it

390 happened, it's happened so I'm good with it." In almost every instance, a discussion of a

391 challenge was followed by an expression of hope or acceptance. "I wasn't happy with it, but

392 then I thought well, this is alright."

394 from the qualitative interviews. The CES-D depression scores (mean=1.36, range $=0-8$ ) from 
the 18 individuals completing the survey did not differ from the HRS national average CES-D score for the unemployed (mean $=1.34$, range $=0-8)$. This suggests that the mental health of the

397 older adults attending the Huntsman Senior Games did not differ from population norms.

398 Though the retirement transition wasn't perfect or easy for many, adjusting and adapting provided keys to ongoing contentment. When asked 'what is the hardest thing about retirement',

400 one woman just laughed. That emotional expression reflected a joy in retirement that was 401 evident in so many individuals as they discussed what they love about retirement life. Prior

402 research has shown a lasting negative effect of unemployment on mental health among older 403 adults (Voss et al., 2017), regardless of whether they returned to work (Gallo et al., 2006). Yet

404 this group of older adults had CES-D depression scores very similar to the national averages for 405 the age group from the HRS comparative sample. While more than half of this sample experienced involuntary retirement and all had pre-retirement unemployment, successful

407 adaptation moved them past deprivation into current joyful living.

\section{Discussion}

Analyzing the volumes of life experience from participating older adults, it is clear that unemployment in pre-retirement is both difficult to measure and complex in its impact. Yet

411 despite the distinct challenges of unemployment and forced retirement, this group of older adults 412 spent little time discussing the episode of struggle and preferred reflecting on the pathways they

413 had found toward joy in retirement. It may be relevant to start with occupational constructs of 414 engagement, participation or "doing" (Wilcock, 1998) as a lens from which to view both the 415 struggle and the adaptation experienced by these retirees. In analysis of the interview transcripts, 416 it became apparent that "doing" in retirement takes on a different meaning, detached from the 417 work and play constructs of earlier life. This is illustrated by one man's answer to a simple 
418 question, "What do you do?" He said, "I'm retired and I don't do anything." Yet if asked about 419 his activities, his 'don't do anything' declaration was clearly false. Querying the construct of

420 'doing' devoid of its depth and richness evoked an answer related to work versus retirement, 421 rather than activity and life engagement more generally. Doing in retirement is incongruent with 422 traditional occupational categories of work and play, reflecting instead dimensions of choice and 423 purpose.

The cultural viewpoint which stressed the importance of productive activity during their 425 working lives was brought up by several of the individuals who experienced unemployment in 426 the pre-retirement years.

Well, working is so much a part of person's life, especially if they like what they do, and they appreciate that they are contributing to society...

429 The strong pull of a work-based identity makes unemployment a significant psychological 430 hurdle. The mechanisms behind a work-based identity are both internal, as occupation shapes the 431 sense of self (Christiansen, 1999), and external through cultural incentives (Thompson, 1967). 432 Thompson's (1967) theory, that there is a Westernized tendency to monetize the time-based 433 mechanism by which labor produces measurable value infers that employed individuals will be 434 viewed with greater esteem than non-working peers. One reason that late-career unemployment 435 may be difficult to measure is because retirement carries less social stigma than unemployment 436 in terms of the loss of work-based value (Hetschko, Knabe, \& Schöb, 2014). The sense of loss 437 related to a work-based identity was described by participants in relation to their unemployment, 438 but not their retirement. ...I don't feel as worthwhile and I have tried to fight against that, but sometimes you know (how) you equate someone paying you with worth? And it's a silly way to feel, but 
I can't help feeling that way to some extent. I'm not as worthy, and I'm not as good because no one is paying me for what I do.

Occupational scientists have discussed the identity shaping aspect of productive occupations as a key component in the relationship between occupation and health (Christiansen, 1999; Jahoda, 1982; Wilcock, 2005). In the unemployment literature, the loss of personal identity was found to be the closest correlate with perceived deprivation from unemployment (Waters \& Moore, 2002). Losing this important form of societal contribution and meaning derived from work can be perceived as devastating. This group of older adults discussed both the struggle of the unemployment experience in terms of personal identity, but also an adaptation that ensued. The conversations with these older adults pointed to a change in occupational attitudes that occurs during the retirement years. To ask about the essence of a person who is retired, we realized that the question of "doing" was not identity based. These retirees stressed the importance of activity and engagement, but their long list of activities (i.e. pickle ball, going to the gym, fixing cars, housekeeping, social clubs, etc.) did not replace the list of identity icons from their prior work lives. Retirees didn't describe themselves in terms of their sporting or social events. When asked 'what do you do?', they didn't say 'I play baseball," or "I'm a bridge champion." Instead, they referred to their doing identity with the general term "retired" or a reference to their prior work life such as "I used to be an accountant". Social roles came up ("I'm a wife," "a father," "a grandmother") when individuals were asked how they would describe themselves, but not with consistency. The lack of connection with current life purposes suggests a misfit of the construct of "doing" when applied to retirees. Despite the frequency of their mentions of activity and engagement, there wasn't a single messenger or container of meaning that replaced the traditional work-based description of a doing identity. 
It has been noted that traditional categorization schemes for occupation (work, play,

465 sleep, etc.) do not capture the complexity of the occupational experience (Jonsson, 2008;

466 Primeau, 1996; Thompson \& Bunderson, 2001). This may be particularly true for the group of

467 individuals who have retired from paid labor. Negotiating changes in occupational engagement

468 and meaning can be particularly challenging for older adults (Heatwole Shank \& Cutchin, 2010).

469 Many of the older adults had lived lives full of productivity and service and spoke with pride

470 when reflecting on their past contributions. But repeatedly many spoke of this time of

471 productivity and engagement as having 'served their time', and that now it was time to pass the

472 torch of service to others. This feeling that the major years of productive labor to society had

473 come to an end in retirement fits the conceptualization that older workers are a burden to a

474 market-economy (Skirbekk, 2004). Freedom from the constraints of obligatory work in a market-

475 economy may also mean freedom to enact occupational balance (Clouston, 2014). Rather than

476 rankling at the idea that they would no longer be relied on for service and productivity, these

477 older adults spoke of fondness of placing themselves on a shelf and letting younger folks do the

478 heavy lifting of productive service to communities. In the process of accepting retirement as a

479 life-stage of non-productivity, they had freed themselves up for pursuits of purposeful and

480 enjoyable activities in sports, sociality, and travel. This conceptual transition to purposeful

481 rather than productive activity requires a retooling of work-based occupational constructs.

An alternative construction for categorizing the nature of occupational experience, which

483 does not rely on a dichotomy between productive work versus non-productive play, may be more

484 relevant to the experience of "doing” in retirement. Jonsson \& Persson's (2006) experiential

485 theory of occupational categories holds that daily balance in exacting, flowing, and calming

486 activity leads to an enhanced quality of life. What constitutes balance will vary based on 
487 individual skills interacting within a context (such as the expectations related to retirement) and 488 influenced by occupational demands. This model might be beneficial in understanding the 489 occupational identity of older adults who have moved into a phase of life which does not have 490 the same social expectations for productivity, and yet inclusion is still essential. Whiteford \& 491 Periera (2012) view occupations as the vehicle for individuals and groups in society to 492 participate and in which inclusion can ultimately be achieved. The transformation from 493 productive labor as a source of value and meaning to inclusive purposeful activity as a sufficient 494 substitute likely depends on culture-bound roles. Given the work-based identity descriptors 495 provided by this sample of retirees, the transition to a purpose-based identity has not fully 496 evolved in the US culture.

This discussion has addressed issues of identity formation and meaning, but a final area

498 of occupational well-being incorporates the issue of control (Doble \& Santha, 2008). Despite 499 having laid a theoretical foundation of the latent benefits of work as the primary source of 500 occupational deprivation (Jahoda, 1982), participant reflections focused rather on issues of 501 choice. The loss of a socially endorsed purpose and social contacts from work were mentioned 502 by a minority of the participants, thus they are not the primary interpretation to arise from these 503 data. The most significant challenges reported by many individuals were the ongoing impact of 504 the unemployment episode on their retirement income and ability to choose their lifestyle. As one respondent reported, "Retirement is what I want to do, but can't afford."

507 benefits model, suggesting that limitations on income and consequent restriction in agency are 508 the mechanism by which unemployment impacts health (Fryer, 1986). The loss of income was a 509 distinct challenge and the timing of late-career unemployment extended the economic impact 
510 (with consequent limitations on choice) into the retirement years. Interviewees reported losing

511 access to pensions that they thought would fund their retirement, taking highly reduced payments

512 on their planned pensions, or having to work at reduced pay rates. Others reported working extra

513 years to make-up the lost income. The data in this study suggested that individuals who felt

514 forced into retirement experienced a limited income that they described as limiting their lifestyle

515 choices, consistent with agency restriction theory. The strong negatives of agency restriction

516 were captured in the comment of one respondent, "So you know it was a horrible feeling, and it

517 might pass, but there was no choice." The importance of having choices was discussed as a

518 significant factor in the happiness and health of retirees (Quine et al., 2007; Rudman et al.,

519 1997). For this group of older adults with pre-retirement unemployment, agency restriction

520 modeled the unemployment deprivation experience with more relevance than the latent benefits

521 of work model.

522 Despite these unemployment based limitations in choice, many respondents still found

523 their retirement years to be a time in which control and choice was more freely available than

524 during their working years. The freedom to choose activities and daily patterns was the most

525 commonly mentioned benefit of retirement among these respondents. Even when income

526 restrictions continued into the retirement years, individuals reported how much they enjoyed

527 their current freedom in time and the ability to choose their daily activities. Some had returned

528 to work to manage the financial difficulties of an early retirement, but most noted that working in

529 retirement was entirely different than working full-time, with more flexibility and freedom and

530 less constrained by income requirements. Several individuals noted that they had let go of some

531 affordances in life to trim their budgets, but it hadn't trimmed their life satisfaction. 
This strong positive theme of choice is subject to two distinct limitations. These interviewees were retired individuals who had already made it past the difficult episode of unemployment and had navigated the majority of consequent change and agency restriction. Additionally, the unpaid, voluntary nature of participation and source of the sample limits the ability to generalize conclusions. The Huntsman World Senior Games incorporates some nonathletic activities (i.e., bridge) but generally draws a crowd of active and involved older adults. These are individuals with enough income to travel and participate, who on average report very good health, and are likely not representative of the range of lifestyle restrictions that may impact older adults on reduced incomes. A sample of 24, particularly given the higher incomes, education, and health levels, in not sufficient for drawing generalized conclusions. Future research is planned to qualitatively examine the impact of late-career unemployment in a more representative sample. Yet even with these cautions on the limitations and the sample characteristics, participants reported on both their prior restrictions in choice as a hardship and the current availability of choice as an asset, suggesting a duality in the experience. The themes of challenge, choice, transition, and resilience may be theoretically relevant and transferable to occupational well-being models for older adults, though may not be empirically generalizable to the population overall due to the sample characteristics.

Conclusions

This study provides insight into the non-economic aspects of late-career unemployment and the implications for well-being as well as insights into the roles of adaptation and resilience in ameliorating its effects. It has been noted that the expenditure of time toward the obligatory task of paid work erodes time and energy resources needed for well-being enhancing activity (Clouston, 2014). Particularly among older adults who may be experiencing a slowing of life 
555 pace, the market-based demands of full-time employment may put added demands on work-life

556 balance. Increasing choices to engage in bridge-employment and flexible work arrangements

557 during the retirement transition may be a useful policy solution to manage the negative effects of

558 late-life unemployment scenarios. This study also adds to evidence that choice and agency play

559 an important role in the life satisfaction of older adults and that there is an ongoing evolution of

560 the construct of "doing" in retirement.

561

562 


\section{References}

564

565

566

567

568

569

570

571

572

573

574

575

576

577

578

579

580

581

582

583

584

585

586

587

588

589

590

591

592

593

594

595

596

597

598

599

600

601

602

603

604

605

606

607
Barber, M. D. (2004). Occupational science and phenomenology: Human activity, narrative and ethical responsibility. Journal of Occupational Science, 11(3), 105-114. doi.org/10.1080/14427591.2004.9686538

Braun, V., \& Clarke, V. (2006). Using thematic analysis in psychology. Qualitative research in psychology, $3(2), 77-101$.

Braun, V., \& Clarke, V. (2014). What can "thematic analysis" offer health and wellbeing researchers? International Journal of Qualitative Studies on Health and Well-being, 2014 Oct 16;9:26152, eCollection. doi.org/10.3402/qhw.v3409.26152.

Burgard, S. A., Ailshire, J. A., \& Kalousova, L. (2013). The Great Recession and Health People, Populations, and Disparities. The ANNALS of the American Academy of Political and Social Science, 650(1), 194-213.

Calvo, E., Haverstick, K., \& Sass, S. A. (2009). Gradual retirement, sense of control, and retirees' happiness. Research on Aging, 31(1), 112-135.

Cheak-Zamora, N. C., Wyrwich, K. W., \& McBride, T. D. (2009). Reliability and validity of the SF-12v2 in the medical expenditure panel survey. Quality of Life Research, 18(6), 727-735.

Chien, S., Campbell, N., Chan, C., Hayden, O., Hurd, M., Main, R., . . Meijer, E. (2015). RAND HRS Data Documentation, Version O. RAND Center for the Study of Aging: Santa Monica, CA, USA.

Christiansen, C. H. (1999). Defining lives: Occupation as identity: An essay on competence, coherence, and the creation of meaning. American Journal of Occupational Therapy, 53(6), 547-558. doi.org/10.5014/ajot.53.6.547

Clark, F., Jackson, J., Carlson, M., Chou, C. P., Cherry, B. J., Jordan-Marsh, M., ... Azen, S. P. (2012). Effectiveness of a lifestyle intervention in promoting the well-being of independently living older people: results of the Well Elderly 2 Randomised Controlled Trial. Journal of Epidemiology and Community Health, 66(9), 782-790. doi:10.1136/jech.2009.099754

Clouston, T. J. (2014). Whose occupational balance is it anyway? The challenge of neoliberal capitalism and work-life imbalance. British Journal of Occupational Therapy, 77(10), 507-515.

Coile, C. C., \& Levine, P. B. (2011). The market crash and mass layoffs: How the current economic crisis may affect retirement. The BE Journal of Economic Analysis \& Policy, 11(1). doi.org/10.2202/1935-1682.2568

Coile, C. C., Levine, P. B., \& McKnight, R. (2012). Recessions, Older Workers, and Longevity: How Long Are Recessions Good For Your Health?: National Bureau of Economic Research.

Creswell, J. W., Klassen, A. C., Plano Clark, V. L., \& Smith, K. C. (2011). Best practices for mixed methods research in the health sciences. Bethesda, MD: National Institutes of Health, 2013, 541-545. doi.org/10.1037/e566732013-001

Doble, S. E., \& Santha, J. C. (2008). Occupational well-being: rethinking occupational therapy outcomes. Canadian Journal of Occupational Therapy. Revue Canadienne D'Ergothérapie, 75(3), 184-190.

Fryer, D. (1986). Employment deprivation and personal agency during unemployment: A critical discussion of Jahoda's explanation of the psychological effects of unemployment. Social Behavior, 1, 3-23.

Gallo, W. T., Bradley, E. H., Dubin, J. A., Jones, R. N., Falba, T. A., Teng, H. M., \& Kasl, S. V. (2006). The persistence of depressive symptoms in older workers who experience involuntary job loss: results from the health and retirement survey. The Journals of Gerontology Series B: Psychological Sciences and Social Sciences, 61(4), S221-228. 
Government Accountability Office. (2012). Unemployed older workers: Many experience challenges regaining employment and face reduced retirement security. Washington, D.C.: Government Accountability Office.

Gerdtham, U. G., \& Johannesson, M. (2003). A note on the effect of unemployment on mortality. Journal of Health Economics, 22(3), 505-518. doi:10.1016/s0167-6296(03)00004-3

Glass, T. A., de Leon, C. M., Marottoli, R. A., \& Berkman, L. F. (1999). Population based study of social and productive activities as predictors of survival among elderly Americans. BMJ, 319(7208), 478-483.

Granados, J. A. T., House, J. S., lonides, E. L., Burgard, S., \& Schoeni, R. S. (2014). Individual joblessness, contextual unemployment, and mortality risk. American Journal of Epidemiology, 180(3), 280287.

Gray, J. M. (1997). Application of the phenomenological method to the concept of occupation. Journal of Occupational Science, 4(1), 5-17.

Heatwole Shank, K., \& Cutchin, M. P. (2010). Transactional occupations of older women aging-in-place: Negotiating change and meaning. Journal of Occupational Science, 17(1), 4-13. doi.org/10.1080/14427591.2010.9686666

Hetschko, C., Knabe, A., \& Schöb, R. (2014). Changing identity: Retiring from unemployment. The Economic Journal, 124(575), 149-166.

Jahoda, M. (1982). Employment and unemployment: $A$ social-psychological analysis (Vol. 1): Cambridge University Press.

Jahoda, M., Lazarsfeld, P., \& Zeisel, H. (1974). Marienthal. The Study of an Unemployed Community: London: Tavistock.

Jin, R. L., Shah, C. P., \& Svoboda, T. J. (1995). The impact of unemployment on health: a review of the evidence. CMAJ: Canadian Medical Association Journal, 153(5), 529-540.

Jonsson, H. (2008). A new direction in the conceptualization and categorization of occupation. Journal of Occupational Science, 15(1), 3-8. doi.org/10.1080/14427591.2008.9686601

Jonsson, H., \& Persson, D. (2006). Towards an experiential model of occupational balance: An alternative perspective on flow theory analysis. Journal of Occupational Science, 13(1), 62-73. doi.org/10.1080/14427591.2006.9686571

Leist, A. K., Hessel, P., \& Avendano, M. (2014). Do economic recessions during early and mid-adulthood influence cognitive function in older age? J Epidemiol Community Health, 68(2), 151-158. doi:10.1136/jech-2013-202843

Matuska, K. M., \& Christiansen, C. H. (2008). A proposed model of lifestyle balance. Journal of Occupational Science, 15(1), 9-19. doi.org/10.1080/14427591.2008.9686602

Moon, J. R., Glymour, M. M., Subramanian, S. V., Avendano, M., \& Kawachi, I. (2012). Transition to retirement and risk of cardiovascular disease: prospective analysis of the US health and retirement study. Social Science \& Medicine, 75(3), 526-530. doi:10.1016/j.socscimed.2012.04.004

NVivo qualitative data analysis Software. (2014). QSR International Pty Ltd.

Primeau, L. A. (1996). Work and leisure: transcending the dichotomy. American Journal of Occupational Therapy, 50(7), 569-577. doi.org/10.5014/ajot.50.7.569

Quine, S., Wells, Y., De Vaus, D., \& Kendig, H. (2007). When choice in retirement decisions is missing: Qualitative and quantitative findings of impact on well-being. Australasian Journal on Ageing, 26(4), 173-179.

Radloff, L. S. (1977). The CES-D scale a self-report depression scale for research in the general population. Applied Psychological Measurement, 1(3), 385-401. 
Rhee, M. K., Mor Barak, M. E., \& Gallo, W. T. (2016). Mechanisms of the Effect of Involuntary Retirement on Older Adults' Self-Rated Health and Mental Health. Journal of Gerontological Social Work, 59(1), 35-55. doi:10.1080/01634372.2015.1128504

Rudman, D. L., Cook, J. V., \& Polatajko, H. (1997). Understanding the potential of occupation: A qualitative exploration of seniors' perspectives on activity. American Journal of Occupational Therapy, 51(8), 640-650.

Salyers, M. P., Bosworth, H. B., Swanson, J. W., Lamb-Pagone, J., \& Osher, F. C. (2000). Reliability and validity of the SF-12 health survey among people with severe mental illness. Medical Care, 38(11), 1141-1150.

Skirbekk, V. (2004). Age and individual productivity: A literature survey. Vienna yearbook of population research, 133-153. doi.org/10.1553/populationyearbook2004s133

Smith, J. A., \& Osborn, M. (2008). Interpretative phenomenological analysis. In G. Breakwell (Ed.), Doing social psychology research (pp. 229-254): British Psychological Society and Blackwell Publishing Ltd. doi.org/10.1002/9780470776278.ch10

Stuckler, D., Basu, S., Suhrcke, M., Coutts, A., \& McKee, M. (2011). Effects of the 2008 recession on health: a first look at European data. Lancet, 378(9786), 124-125. doi:10.1016/s01406736(11)61079-9

Sullivan, D., \& Von Wachter, T. (2009). Job displacement and mortality: An analysis using administrative data. The Quarterly Journal of Economics, 124(3), 1265-1306.

Thompson, E. P. (1967). Time, work-discipline, and industrial capitalism. Past \& Present 38(1), 56-97. doi.org/10.1093/past/38.1.56

Thompson, J. A., \& Bunderson, J. S. (2001). Work-nonwork conflict and the phenomenology of time beyond the balance metaphor. Work and Occupations, 28(1), 17-39.

van der Heide, I., van Rijn, R. M., Robroek, S. J., Burdorf, A., \& Proper, K. I. (2013). Is retirement good for your health? A systematic review of longitudinal studies. BMC Public Health, 13, 1180. doi:10.1186/1471-2458-13-1180

Van Horn, C. E., Corre, N., \& Heidkamp, M. (2011). Older workers, the great recession, and the impact of long-term unemployment. Public Policy \& Aging Report, 21(1), 29-33.

Van Solinge, H. (2007). Health change in retirement a longitudinal study among older workers in the Netherlands. Research on Aging, 29(3), 225-256.

Voss, M. W., Birmingham, W. C., Wadsworth, L., Chen, W., Bounsanga, J., Gu, Y., \& Hung, M. (2017). Honest Labor Bears a Lovely Face: Will Late-Life Unemployment Impact Health and Satisfaction in Retirement? Journal of Occupational and Environmental Medicine, 59(2):184-190. doi.org/10.1097/JOM.0000000000000933

Waters, L. E., \& Moore, K. A. (2002). Reducing latent deprivation during unemployment: The role of meaningful leisure activity. Journal of Occupational and Organizational Psychology, 75(1), 15-32.

Weisman, M.-L. (1999). The history of retirement, from early man to AARP. New York Times, 21.

Whiteford, G. E., \& Pereira, R. B. (2012). Occupation, inclusion and participation. Occupational science: Society, inclusion, participation, 185-207.

Wilcock, A. A. (1998). Reflections on doing, being and becoming. Canadian Journal of Occupational Therapy, 65(5), 248-256. doi.org/10.1177/000841749806500501

Wilcock, A. A. (2005). Occupational science: Bridging occupation and health. Canadian Journal of Occupational Therapy, 72(1), 5-12. doi.org/10.1177/000841740507200105 